\title{
A hybrid fuzzy stochastic analytical hierarchy process (FSAHP) approach for evaluating ballast water treatment technologies
}

\author{
Liang Jing, Bing Chen *, Baiyu Zhang and Hongxuan Peng
}

\begin{abstract}
Background: Environmental decisions can be complex because of the inherent trade-offs among environmental, social, ecological, and economic factors. This paper presents a novel hybrid fuzzy stochastic analytical hierarchy process (FSAHP) approach to aid decision making by incorporating fuzzy and stochastic uncertainty into the traditional analytic hierarchy process (AHP). A case study related to ballast water management is used to demonstrate the applicability of the proposed approach. Nine experts from government ministries and academic institutions are invited to evaluate five treatment technologies (i.e., heat treatment, ultraviolet, ozone, ultrasound, and biocide) based on a number of criteria such as efficacy, capital cost, and human risk.

Results: The experts' preferences over the set of alternatives are represented as linguistic terms instead of numerical values. The beta-PERT distribution is adopted to approximate the probability density functions of the values of their inputs. Statistical analysis indicates that ultraviolet has the highest score $(0.22-0.24)$ in most replications and its overlap with the second-best alternative is statistically negligible. Ozone, ultrasound, and heat treatment are mostly found as the second-, third-, and fourth-best alternatives with considerable overlaps that may be reduced if more experts are involved.
\end{abstract}

Conclusions: As compared with the traditional AHP, the proposed FSAHP approach can not only take into account linguistic information but also capture the uncertainty associated with insufficient information and biased opinions in group decision-making problems.

Keywords: FSAHP approach; Fuzzy; Stochastic; Ballast water management; Group decision-making

\section{Background}

Environmental decisions can be complex because of the inherent trade-offs among environmental, social, ecological, and economic factors [1,2]. Many multi-criteria decision making (MCDM) approaches have been developed to facilitate decision making under uncertainty [3-5]. Kornyshova and Salinesi [6] classified them into categories such as outranking methods, analytic hierarchy process, multiattribute utility theory, weighting methods, fuzzy methods, and multiobjective programming. Among them, the analytic hierarchy process (AHP), first proposed by Saaty [7], is one of the most widely used MCDM approaches. It structures the

\footnotetext{
* Correspondence: bchen@mun.ca

Faculty of Engineering and Applied Science, Memorial University of Newfoundland, St. John's, NL A1B 3X5, Canada
}

rational analysis of decision making by dividing a problem into hierarchies including goal, criteria, subcriteria (if any), and decision alternatives. One of the most important features or, in other words, the strength of the AHP revolves around the possibility of evaluating quantitative as well as qualitative criteria and alternatives on the same preference scale. Pairwise comparison judgments are given by decision makers using numerical, verbal or graphical scales and are subsequently synthesized to obtain the overall priorities. This comparison enables the AHP to capture subjective and quantitative judgment made by decision makers. Many attempts have been reported in the literature to apply the AHP in problems with high complexity and uncertainty, especially in the environmental sector [8-13].

However, the AHP has been criticized for its inability to quantify the uncertainty associated with decision 
making [14]. Banuelas and Antony [15] highlighted that the basic theory of the AHP does not allow any statistical conclusion to be drawn. Rosenbloom [16] stated that a small difference in the utilities of alternatives may not be appropriate to conclude that one alternative is superior to the other. Carlucci and Schiuma [17] argued that the AHP is not able to address the interactions and feedback dependencies between the elements of a decision problem. In addition, in many real-world applications, the available information is imprecise, incomplete and occasionally unreliable due to the unquantifiable nature of data or lack of knowledge. Human experts tend to use linguistic terms (e.g., good, poor, excellent) to express their judgments which can not be handled effectively using crisp scales.

To overcome the aforementioned limitations, much research effort has therefore been directed towards taking uncertainties (e.g., fuzzy sets and probability distributions) into account in the AHP. On one hand, to capture linguistic information, Yu [18] employed an absolute term linearization technique and a fuzzy rating expression into a GP-AHP model for solving fuzzy AHP problems. Tolga et al. [13] combined the use of fuzzy set theory with the AHP to address the uncertainty of assigning crisp concepts in decision-making topics. Tesfamariam and Sadiq [19] incorporated uncertainty into the AHP using fuzzy arithmetic operations for environmental risk management. Chowdhury and Husain [8] integrated fuzzy set theory, the AHP, and the concept of entropy to select the best management plan for a drinking water facility. Kaya and Kahraman [10] proposed a hybrid fuzzy AHP-ELECTRE approach for modeling the uncertainty of linguistic expression. On the other hand, to deal with insufficient information and opinion difference in group decisionmaking processes, pairwise comparison elements were suggested to be viewed as random variables and computed via Monte Carlo simulation by Rosenbloom [16], Eskandari and Rabelo [20] and Jing et al. [21]. To date, triangular distribution is the most commonly used distribution for modeling expert judgment in the AHP [15,22]. However, it may place too much emphasis on the most likely value at the expense of the values to either side [23]. It is possible to overcome this disadvantage of the triangular distribution by using the beta-PERT distribution. The beta-PERT distribution has also been widely used for modeling expert judgments and providing a close fit to normal distributions with less demand for data [24,25]. Although various types of uncertainty have been discussed in the literature, there has been no study investigating the feasibility of incorporating both fuzzy and stochastic uncertainty into the AHP.

In response to this, in this paper, a hybrid fuzzy stochastic analytical hierarchy process (FSAHP) approach is developed by integrating the beta-PERT distribution, fuzzy set theory, pairwise comparison and Monte Carlo simulation. A real-world case study for ballast water management is presented to test the feasibility and efficiency of the proposed approach in a group decision-making environment. Ballast water is carried by ships to acquire the optimum operating depth of the propeller and to maintain maneuverability and stability [26]. It is recognized as the principle source of invasive species and pollutants in coastal freshwater and marine ecosystems, causing severe negative effects on the environment and human health [27-30]. To address the associated concerns, the International Maritime Organization (IMO) has adopted many legal instruments whereby ships will be required to establish a ballast water management system between 2009 and 2016 [31]. Many treatment technologies such as filtration, heat treatment, hydrocyclone, ultraviolet, ozonation, oxidization, electric pulse, and deoxygenation have been tested and applied to remove unwanted species and pollutants from ballast water [29]. However, Gregg and Hallegraeff [32] argued that no treatment option had been shown fully biologically effective, environmentally friendly, safe and practical for onboard applications. In addition, the performance of most treatment processes is likely to be affected by the cold environment and unpredictable weather conditions $[26,29]$. The evaluation of their applicability and associated risk is of paramount importance and lacks in-depth research. How to choose the best technology from a sustainability metrics perspective still exists as a challenge to the government and other public bodies with environmental responsibilities.

\section{Methods}

\section{Fuzzy sets and fuzzy numbers}

Zadeh [33] first introduced the concept of fuzzy set theory which was oriented to the rationality of uncertainty due to imprecision or vagueness. Fuzzy set theory is an extension of the classical set theory in which elements have grades of membership ranging from 0 to 1 . A triangular fuzzy number (TFN) is defined by its membership function $\mu(x)$ as

$$
\mu(x)=\left\{\begin{array}{cc}
(x-a) /(b-a), & a \leq x \leq b \\
(x-c) /(b-c), & b \leq x \leq c \\
0, & \text { otherwise }
\end{array}\right.
$$

where $a, b$ and $c$ denote the minimum, most likely, and maximum values, respectively. Fuzzy numbers are well suited to represent the imprecise nature of judgments, such as linguistic terms used by human experts. Some basic arithmetic operations of fuzzy numbers can be found at Kaufmann et al. [34].

\section{Stochastic programming}

Monte Carlo simulation, which applies probability theory to address variable and uncertain phenomena, relies 
on statistical representation of available information. It has been widely applied to obtain more detailed information for systems that are too complex to be solved analytically. Monte Carlo simulation in its simplest form involves random sampling from a probability distribution. Various probability distributions (e.g., uniform, normal, beta, and lognormal) have been used in connection with Monte Carlo simulation to model the uncertainty of environmental systems. Banuelas and Antony [15] presented a modified analytic hierarchy process with triangular probability distribution to include uncertainty in the judgments. Li and Chen [35] developed a fuzzy-stochastic-interval linear programming (FSILP) approach for supporting municipal solid waste management by tackling uncertainties expressed in normal probability distributions, fuzzy membership functions and discrete intervals. Jing et al. [25] proposed a Monte Carlo simulation aided analytic hierarchy process (MC-AHP) approach by employing the beta-PERT distribution to prioritize nonpoint source pollution mitigation strategies. Jing et al. [21] further integrated the uniform distribution with interval judgment to a hybrid stochastic-interval analytic hierarchy process (SIAHP) framework for group decision making on wastewater reuse. In this paper, the beta-PERT distribution is employed to model expert judgment. It uses the most likely, minimum, and maximum values of expert estimates to generate a distribution that more closely resembles realistic probability distribution.

\section{Fuzzy stochastic analytic hierarchy process (FSAHP)}

The proposed FSAHP approach is capable of capturing not only a human's appraisal of ambiguity but also the uncertainty introduced by the lack of information or scattered opinions. Experts' linguistic assessments are aggregated to approximate a series of beta-PERT distributions for randomized fuzzy pairwise comparisons.
Monte Carlo simulation is then used to generate random fuzzy pairwise comparison matrices (FPCMs), calculate the fuzzy weights, and produce the final scores for each decision alternative. The detailed steps are summarized as follows:

Step 1: Structure the decision problem into a hierarchy of interrelated subproblems that can be analyzed independently. The hierarchy usually includes a main goal, criteria, and alternatives, from the top to the bottom. Each criterion may be further decomposed to a number of lower-level subcriteria as a new level. The goal, criteria, subcriteria (if any), and alternatives can be determined through literature reviews and collective discussions.

Step 2: Linguistic judgments on each alternative and criterion with respect to the elements on the level immediately above can be obtained from experts through questionnaires, surveys, interviews, expert panels, and direct observations. Instead of using a crisp ratio scale, seven TFNs (Figure 1) are used to represent linguistic terms with the expectation that experts will feel more comfortable using such terms in their assessment. It should be noted that such a verbal clarification becomes impractical when too many rating scales (e.g., 10-point format) are involved because the level of agreement becomes too fine to be easily expressed in words [36].

Step 3: For the assessment of each alterative and criterion, the number of TFNs should be equal to the number of experts. The minimum $(a)$, most likely $(b)$ and maximum $(c)$ values of the TFNs are aggregated into three individual groups. In order to generate random TFNs, Equations $2-5$ are used to approximate an independent beta-PERT distribution for each group.

$$
\operatorname{mean}=\frac{\min +4 \operatorname{modal}+\max }{N}
$$

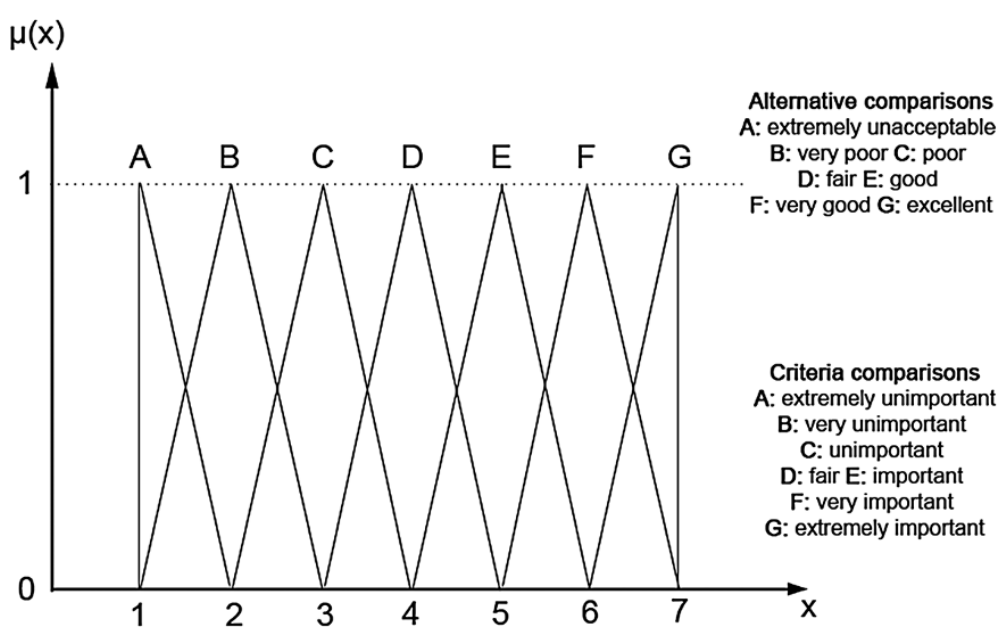

Figure 1 Membership spread of linguistic scales. 


$$
\begin{aligned}
& \text { stdev }=\frac{\text { max }- \text { min }}{N} \\
& \alpha=\left(\frac{\text { mean }- \text { min }}{\text { max }- \text { min }}\right)\left(\frac{(\text { mean }- \text { min })(\text { max }- \text { mean })}{s t d e v^{2}}-1\right) \\
& \beta=\left(\frac{\text { max }- \text { mean }}{\text { mean }- \text { min }}\right) * \alpha
\end{aligned}
$$

where mean, min, modal, max, stdev denote the mean, smallest, most probable, largest values, and standard deviations of $a, b$, and $c$, respectively; $N$ is the number of experts; $\alpha$ and $\beta$ are the shape factors. Equations $6-8$ are then used to generate random numbers (i.e., random ${ }_{a}$, random $_{b}$, random $_{c}$ ) that follow the beta-PERT distributions for $a, b$, and $c$, respectively. It is noteworthy that the triangular shape needs to be verified to validate these random numbers.

$$
\begin{aligned}
\operatorname{random}_{a}= & \min _{a}+\text { betarnd }\left(\alpha_{a}, \beta_{a}\right) \\
& *\left(\max _{a}-\min _{a}\right) \\
\operatorname{random}_{b}= & \min _{b}+\operatorname{betarnd}\left(\alpha_{b}, \beta_{b}\right) \\
& *\left(\max _{b}-\min _{b}\right) \\
\operatorname{random}_{c}= & \min _{c}+\operatorname{betarnd}\left(\alpha_{c}, \beta_{c}\right) \\
& *\left(\max _{c}-\min _{c}\right)
\end{aligned}
$$

where betarnd denotes standard Matlab function (i.e., beta distribution) which returns a random number between 0 and 1.

Step 4: Set up fuzzy pairwise comparison matrices (FPCMs) for each hierarchy level based on fuzzy arithmetic. For example, when $m$ alternatives $\left(C_{1} \ldots C_{m}\right)$ on a given level are evaluated against each other with regard to the $p^{\text {th }}$ criterion $(p=1,2,3 \ldots \mathrm{n})$ on the preceding level, an $m \times m$ FPCM is obtained as below

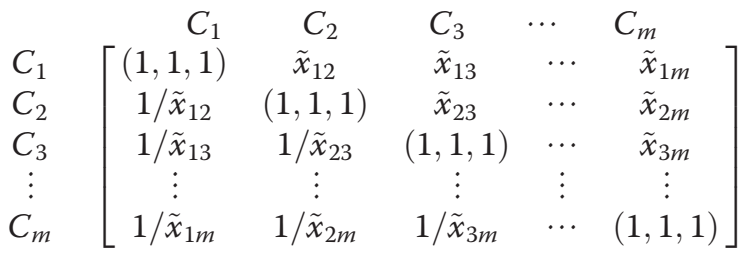

To calculate each non-diagonal fuzzy element (e.g., $\tilde{x}_{13}$ ), the dominance of one alternative or criterion over another is determined by the division of two TFNs. For example, if the random TFNs for $C_{1}$ and $C_{3}$ are $\left(a_{1}, b_{1}, c_{1}\right)$ and $\left(a_{3}, b_{3}\right.$, $\left.c_{3}\right)$, respectively, then $\tilde{x}_{13}=\left(a_{1} / c_{3}, b_{1} / b_{3}, c_{1} / a_{3}\right)$ and $1 /$ $\tilde{x}_{13}=\left(a_{3} / c_{1}, b_{3} / b_{1}, c_{3} / a_{1}\right)$.
Step 5: Calculate the fuzzy weights of each FPCM. For example, in Equation 9, the geometric means of each row and the corresponding fuzzy weights are obtained using Equations 10-13. The weight assessing method by geometric mean is applied because of its simplicity and ease when dealing with fuzzy matrices [10].

$$
\begin{aligned}
a_{i} & =\left[\prod_{j=1}^{m} a_{i j}\right]^{1 / m} ; b_{i}=\left[\prod_{j=1}^{m} b_{i j}\right]^{1 / m} ; c_{i} \\
& =\left[\prod_{j=1}^{m} c_{i j}\right]^{1 / m} \text { for } i=1,2, \ldots, m \\
a_{\text {sum }} & =\sum_{i=1}^{m} a_{i} ; b_{\text {sum }}=\sum_{i=1}^{m} b_{i} ; c_{\text {sum }}=\sum_{i=1}^{m} c_{i} \\
\tilde{w}_{\text {ip }} & =\left(\frac{a_{i}}{c_{\text {sum }}}, \frac{b_{i}}{b_{\text {sum }}}, \frac{c_{i}}{a_{\text {sum }}}\right) \text { for } i=1,2, \ldots, m
\end{aligned}
$$

where $a_{i j}, b_{i j}$, and $c_{i j}$ are the minimum, most likely, and maximum values of each non-diagonal fuzzy element $\tilde{x}_{i j}$, respectively; $m$ is the size of the FPCM or the number of decision alternatives; $a_{i}, b_{i}$, and $c_{i}$ are the geometric means of the minimum, most likely, and maximum values of the fuzzy elements on the $i^{\text {th }}$ row, respectively; $a_{\text {sum }}, b_{\text {sum }}$, and $c_{\text {sum }}$ are the sum of $a_{i}, b_{i}$, and $c_{i}$, respectively; and $\tilde{w}_{i p}$ are the fuzzy weights of the $i^{\text {th }}$ alternative against the $p^{\text {th }}$ criterion. Repeating this step to obtain all other $\tilde{w}_{i p}$ and $\tilde{w}_{p}$, which are the fuzzy weights of the $p^{t h}$ criterion in terms of the goal.

Step 6: As with the traditional AHP, the proposed FSAHP approach also measures the inconsistency of each FPCM. Due to the presence of fuzzy numbers, the traditional consistency algorithms are not effective in addressing such uncertainties. Hence, in this paper, a new inconsistency index $\left(C_{F}\right)$ based on the distance of the matrix to a specific consistent matrix is adopted from Ramík and Korviny [37].

$$
\begin{aligned}
& s_{i}^{L}=\min _{i}\left\{\frac{b_{i}}{a_{i}}\right\} \cdot \frac{a_{i}}{b_{\text {sum }}} \\
& s_{i}^{M}=\frac{b_{i}}{b_{\text {sum }}} \\
& s_{i}^{U}=\max _{i}\left\{\frac{b_{i}}{c_{i}}\right\} \cdot \frac{c_{i}}{b_{\text {sum }}} \\
& C I_{F}=\gamma \cdot \max _{i, j}\left\{\max \left\{\left|\frac{s_{i}^{L}}{s_{j}^{U}}-a_{i j}\right|,\left|\frac{s_{i}^{M}}{s_{j}^{M}}-b_{i j}\right|,\left|\frac{s_{i}^{U}}{s_{j}^{L}}-c_{i j}\right|\right\}\right\}
\end{aligned}
$$




$$
\begin{aligned}
& \gamma=\frac{1}{\max \left\{\sigma-\sigma^{(2-2 m) / m}, \sigma^{2}\left(\left(\frac{2}{m}\right)^{2 /(m-2)}-\left(\frac{2}{m}\right)^{m /(m-2)}\right)\right\}} \\
& \text { if } \sigma<\left(\frac{m}{2}\right)^{m /(m-2)} \\
& 1
\end{aligned}
$$

where $s_{i}^{L}, s_{i}^{M}$, and $s_{i}^{U}$ are the minimum, most likely, and maximum values of the optimal solution that has the minimal measure of fuzziness, respectively; $\sigma$ is the linguistic scale (i.e., $[1 / 7,7]$ in this study); $\gamma$ is the normality constant; $C I_{F}$ is the inconsistency index of a FPCM such that a value of 0.1 or less is considered to be acceptable, otherwise the FPCM should be revised.

Step 7: The overall fuzzy priorities $\tilde{w}_{i}$ of the $i^{\text {th }}$ alternative can be calculated by aggregating the weights throughout the hierarchy:

$$
\tilde{w}_{i}=\sum_{p=1}^{n} \tilde{w}_{i p} \times \tilde{w}_{p}
$$

where $\tilde{w}_{i p}$ are the fuzzy merits of the $i^{\text {th }}$ alternative with regard to the $p^{t h}$ criterion, respectively; $\tilde{w}_{p}$ are the fuzzy weights of the $p^{t h}$ criterion against the goal; and $n$ is the number of evaluation criteria.

Step 8: Defuzzify $\tilde{w}_{i}$ by using the center of gravity (COG) method and rank the decision alternatives based on their normalized crisp overall scores $w_{i}$.

$$
\begin{aligned}
w_{i}^{*}=\frac{\int_{a}^{c} x \mu_{\tilde{w}_{i}}(x) d x}{\int_{a}^{c} \mu_{\tilde{w}_{i}}(x) d x} \\
w_{i}=\frac{w_{i}^{*}}{\sum_{i=1}^{m} w_{i}^{*}}
\end{aligned}
$$

where $w_{i}^{*}$ are the crisp overall scores of the $i^{\text {th }}$ alternative; $a$ and $c$ denote the support of $\tilde{w}_{i} ; \mu_{\tilde{w}_{i}}(x)$ are the corresponding membership functions of $\tilde{w}_{i}$; and $w_{i}$ are the normalized crisp overall scores of each decision alternative and are sequenced from high to low in the order of 1 to 5 . To validate this ranking scheme, or in other words, the defuzzification results, Chen's fuzzy ranking method is also employed to further compare the overall fuzzy priorities $\tilde{w}_{i}$ and rank them from the highest to the lowest [38].

Step 9: Repeat Steps 4 to 8 for a number of iterations (e.g., 1000, 5000), the overall scores of alternatives can be obtained and plotted as probability density functions rather than as point values.

\section{Case study}

This case study was conducted to demonstrate the applicability and effectiveness of the proposed FSAHP approach in addressing uncertainty in the context of group decision-making. A cargo shop was assumed to be required for an onboard ballast water treatment system in order to operate in the North Atlantic. The decision alternatives and evaluation criteria were determined based on literature review and discussion with experts from governmental ministries and academic institutions. The experts were further invited to fill out the questionnaire on the basis of linguistic terms. Their opinions were analyzed and interpreted to facilitate the implementation of the FSAHP approach.

\section{Hierarchy structure}

As depicted in Figure 2, the goal was to select the best onboard treatment technology in order to eliminate invasive microorganisms and to remove water soluble organics from ballast water, particularly in the harsh environments. Five treatment technologies including heat treatment, ultraviolet (UV), ozone, ultrasound, and biocide were chosen [26-30]. Heat treatment is capable of killing invasive species embedded in sediment that has accumulated at the bottom of the ballast tanks. It should be pointed out that discharging warm water potentially threatens biological communities and a complete treatment process may take hours or days, which is not always practical. Despite the potential threats posed by mercury contamination and genetic mutation, UV manages to eliminate microorganisms by breaking chemical bonds in DNA and RNA molecules and cell proteins [29]. Recently, ozone has been widely employed in removing microorganisms from ballast water. The often-cited disadvantages of using ozone as a disinfectant have been reported as the possible formation of toxic byproducts, low solubility, and high instability [39]. Ultrasound can induce the collapse of microscopic gas bubbles in the exposed liquid and lead to the rupture of cell membranes, yet it is less effective in killing some microorganisms such as bacteria [40]. Many chemical biocides have been documented as possible treatment options to the problem of ballast-mediated invasive species. However, some concerns, such as risks from storage and handling, high operational and material cost, and possible discharge of toxic residues need to be taken into account [32]. Based on the recommendations from literature $[29,41,42]$ and expert opinions, in this study, eight evaluation criteria including efficacy on microorganisms, efficacy on organic pollutants, adaptability to harsh environment, capital cost, operation and maintenance (O\&M) cost, human health risk, ecological risk, and waste production were chosen. 


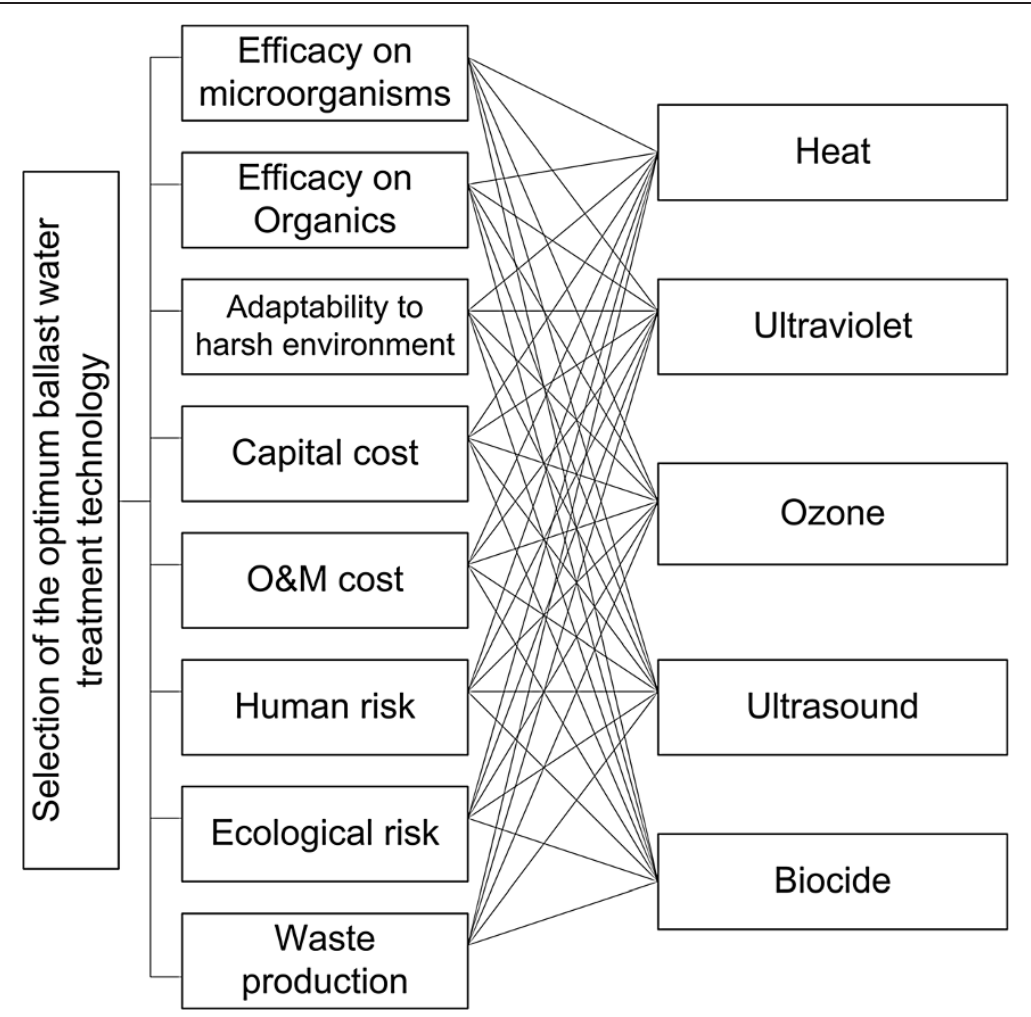

Figure 2 Hierarchy structure of the ballast water treatment technology selection problem.

\section{Data acquisition}

In the absence of quantitative data about each alternative, experts' qualitative judgments were used to measure the priorities of alternatives. The linguistic assessments for the qualitative attributes were provided by nine local experts from governmental ministries (environmental division) and academic institutions (professors and graduate students at Memorial University of Newfoundland). They were asked to rate the performance of each alternative and the importance of each criterion using the linguistic scales provided in Figure 1. Tables 1 and 2 summarize the linguistic assessments made by each participating expert. These assessments were aggregated in groups such that the beta-PERT distributions of each group can be estimated to generate

\begin{tabular}{|c|c|c|c|c|c|}
\hline \multirow{2}{*}{ Heat } & \multirow{2}{*}{$\begin{array}{c}\text { Heat } \\
(1,1,1)\end{array}$} & $\begin{array}{c}\text { Ultraviolet } \\
(2,3,4)\end{array}$ & $\begin{array}{l}\text { Ozone } \\
(2,3,4)\end{array}$ & $\begin{array}{l}\text { Ultrasound } \\
(2,3,4)\end{array}$ & $\begin{array}{l}\text { Biocide } \\
(2,3,4)\end{array}$ \\
\hline & & $\overline{(6,7,7)}$ & $\overline{(6,7,7)}$ & $\overline{(4,5,6)}$ & $\overline{(5,6,7)}$ \\
\hline \multirow{2}{*}{ Ultraviolet } & {$[(2,3,4)]^{-1}$} & \multirow{2}{*}{$(1,1,1)$} & $(6,7,7)$ & $(6,7,7)$ & $(6,7,7)$ \\
\hline & {$[\overline{(6,7,7)}\rfloor$} & & $\overline{(6,7,7)}$ & $\overline{(4,5,6)}$ & $\overline{(5,6,7)}$ \\
\hline \multirow{2}{*}{ Ozone } & {$[(2,3,4)]^{-1}$} & {$[\underline{(6,7,7)}]^{-1}$} & \multirow{2}{*}{$(1,1,1)$} & $(6,7,7)$ & $(6,7,7)$ \\
\hline & {$[\overline{(6,7,7)}]$} & {$[\overline{(6,7,7)}]_{-1}$} & & $\overline{(4,5,6)}$ & $\overline{(5,6,7)}$ \\
\hline \multirow{2}{*}{ Ultrasound } & {$[(2,3,4)]^{-1}$} & {$[(6,7,7)]^{-1}$} & {$[(6,7,7)]^{-1}$} & \multirow{2}{*}{$(1,1,1)$} & $(4,5,6)$ \\
\hline & $\lfloor\overline{(4,5,6)}$ & $\lfloor\overline{(4,5,6)}\rfloor$ & {$[\overline{(4,5,6)}]$} & & $\overline{(5,6,7)}$ \\
\hline \multirow{2}{*}{ Biocide } & {$[(2,3,4)]^{-1}$} & {$[(6,7,7)]^{-1}$} & {$[(6,7,7)]^{-1}$} & {$[(4,5,6)]^{-1}$} & \\
\hline & {$[\overline{(5,6,7)}]$} & $\overline{(5,6,7)}]$ & {$[\overline{(5,6,7)}\rfloor$} & $\lfloor\overline{(5,6,7)}\rfloor$ & $(1,1,1$ \\
\hline
\end{tabular}

random TFNs. For example, the performance of heat, ultraviolet, ozone, ultrasound and biocide with respect to their efficacy on microorganisms was randomly generated as $C$ $(2,3,4), G(6,7,7), G(6,7,7), E(4,5,6)$ and $F(5,6,7)$, respectively. To obtain the corresponding FPCM (Equation 21), elements in the first row were given by the fuzzy comparisons between the performance of heat $(2,3,4)$ and all the others, respectively. The consistency of this FPCM was less than 0.1, which was acceptable, and the fuzzy weights of each alternative were able to be calculated. It should be noted that the number of Monte Carlo iterations used for this case study was determined as 1000 by taking time constraints and the efficiency of convergence into account [22]. 
Table 1 Expert assessment for ballast water treatment technologies

\begin{tabular}{|c|c|c|c|c|c|c|c|c|c|c|}
\hline \multirow[t]{2}{*}{ Criteria } & \multirow[t]{2}{*}{ Alternatives } & \multicolumn{9}{|c|}{ Expert assessment } \\
\hline & & 1 & 2 & 3 & 4 & 5 & 6 & 7 & 8 & 9 \\
\hline \multirow{5}{*}{$\begin{array}{l}\text { Efficacy on } \\
\text { microorganisms }\end{array}$} & Heat & $C$ & $D$ & $B$ & $B$ & $C$ & $C$ & $D$ & $C$ & C \\
\hline & Ultraviolet & G & $F$ & G & G & G & G & $\mathrm{F}$ & $\mathrm{F}$ & $\mathrm{F}$ \\
\hline & Ozone & G & G & $E$ & G & G & $\mathrm{F}$ & $F$ & G & $\mathrm{F}$ \\
\hline & Ultrasound & $E$ & $E$ & $\mathrm{~F}$ & $E$ & $\mathrm{~F}$ & $\mathrm{D}$ & $E$ & $E$ & $E$ \\
\hline & Biocide & $F$ & G & G & $\mathrm{F}$ & $\mathrm{F}$ & G & $E$ & $\mathrm{~F}$ & G \\
\hline \multirow[t]{5}{*}{ Efficacy on organics } & Heat & B & A & A & C & C & B & $C$ & C & B \\
\hline & Ultraviolet & $\mathrm{F}$ & $E$ & G & $\mathrm{F}$ & G & $\mathrm{F}$ & $F$ & G & $\mathrm{F}$ \\
\hline & Ozone & $\mathrm{F}$ & G & $E$ & D & $\mathrm{F}$ & $E$ & $\mathrm{~F}$ & G & $E$ \\
\hline & Ultrasound & $E$ & $E$ & D & $E$ & D & $E$ & $\mathrm{D}$ & E & C \\
\hline & Biocide & B & B & A & B & B & $B$ & $C$ & B & A \\
\hline \multirow{5}{*}{$\begin{array}{l}\text { Adaptability to harsh } \\
\text { environment }\end{array}$} & Heat & C & B & D & C & B & $C$ & $C$ & B & C \\
\hline & Ultraviolet & $\mathrm{F}$ & $E$ & G & $\mathrm{F}$ & $\mathrm{F}$ & $E$ & $\mathrm{~F}$ & $E$ & $\mathrm{~F}$ \\
\hline & Ozone & $F$ & $E$ & $E$ & $F$ & G & D & $E$ & $\mathrm{~F}$ & G \\
\hline & Ultrasound & $E$ & $E$ & F & D & $E$ & D & $E$ & D & D \\
\hline & Biocide & $\mathrm{D}$ & D & $F$ & $E$ & $\mathrm{D}$ & $E$ & $\mathrm{D}$ & C & D \\
\hline \multirow[t]{5}{*}{ Capital cost } & Heat & $\mathrm{F}$ & D & $E$ & $E$ & $\mathrm{~F}$ & $E$ & $\mathrm{~F}$ & $E$ & $E$ \\
\hline & Ultraviolet & $\mathrm{D}$ & $E$ & D & $E$ & D & B & $D$ & D & C \\
\hline & Ozone & C & D & C & D & C & $C$ & C & B & C \\
\hline & Ultrasound & B & C & B & C & D & $C$ & D & B & D \\
\hline & Biocide & G & $F$ & F & $E$ & G & $F$ & $E$ & $F$ & $E$ \\
\hline \multirow[t]{5}{*}{ O\&M cost } & Heat & $\mathrm{F}$ & G & $F$ & $E$ & $E$ & G & $E$ & $\mathrm{~F}$ & G \\
\hline & Ultraviolet & D & $E$ & E & D & D & $E$ & D & $E$ & $E$ \\
\hline & Ozone & $C$ & C & C & D & C & $E$ & $C$ & D & C \\
\hline & Ultrasound & C & B & C & C & $D$ & $\mathrm{D}$ & B & C & D \\
\hline & Biocide & $\mathrm{D}$ & $E$ & D & $\mathrm{F}$ & $\mathrm{F}$ & $E$ & D & $\mathrm{E}$ & $\mathrm{F}$ \\
\hline \multirow[t]{5}{*}{ Human risk } & Heat & G & $F$ & G & $E$ & $\mathrm{~F}$ & $F$ & $E$ & E & $\mathrm{F}$ \\
\hline & Ultraviolet & C & C & D & C & D & C & D & C & B \\
\hline & Ozone & C & D & B & D & $E$ & $\mathrm{D}$ & $E$ & C & $\mathrm{D}$ \\
\hline & Ultrasound & B & D & D & C & $\mathrm{D}$ & $D$ & $E$ & D & C \\
\hline & Biocide & $B$ & B & C & C & $\mathrm{D}$ & C & C & D & B \\
\hline \multirow[t]{5}{*}{ Ecological risk } & Heat & C & D & B & C & D & $E$ & C & $E$ & $\mathrm{D}$ \\
\hline & Ultraviolet & $\mathrm{D}$ & $F$ & D & $E$ & $\mathrm{~F}$ & G & $F$ & D & D \\
\hline & Ozone & $F$ & $E$ & D & $E$ & $E$ & $F$ & $F$ & D & $E$ \\
\hline & Ultrasound & $E$ & D & $E$ & D & $E$ & $\mathrm{D}$ & $E$ & D & $\mathrm{D}$ \\
\hline & Biocide & C & B & $E$ & D & C & C & D & C & C \\
\hline \multirow[t]{5}{*}{ Waste production } & Heat & $E$ & D & D & D & C & D & $E$ & D & C \\
\hline & Ultraviolet & $F$ & G & $F$ & $E$ & $F$ & G & G & $F$ & $E$ \\
\hline & Ozone & $\mathrm{D}$ & $E$ & D & D & $E$ & $E$ & $E$ & $\mathrm{~F}$ & $\mathrm{~F}$ \\
\hline & Ultrasound & $\mathrm{D}$ & C & C & C & D & $\mathrm{D}$ & $E$ & D & $E$ \\
\hline & Biocide & $C$ & B & C & B & D & C & $E$ & D & B \\
\hline
\end{tabular}

Table 2 Expert assessment for evaluation criteria

\begin{tabular}{|c|c|c|c|c|c|c|c|c|c|c|}
\hline \multirow[t]{2}{*}{ Goal } & \multirow[t]{2}{*}{ Criteria } & \multicolumn{9}{|c|}{ Expert assessment } \\
\hline & & 1 & 2 & 3 & 4 & 5 & 6 & 7 & 8 & 9 \\
\hline \multirow[t]{8}{*}{$\begin{array}{l}\text { Best treatment } \\
\text { technology }\end{array}$} & $\begin{array}{l}\text { Efficacy on } \\
\text { microorganisms }\end{array}$ & G & $\mathrm{F}$ & $\mathrm{F}$ & $E$ & $\mathrm{~F}$ & $E$ & G & $E$ & $\mathrm{~F}$ \\
\hline & Efficacy on organics & E & C & D & E & $\mathrm{F}$ & $\mathrm{F}$ & $\mathrm{D}$ & $\mathrm{F}$ & D \\
\hline & $\begin{array}{l}\text { Adaptability to harsh } \\
\text { environment }\end{array}$ & $\mathrm{F}$ & $\mathrm{F}$ & G & $\mathrm{F}$ & $E$ & $\mathrm{D}$ & $\mathrm{E}$ & C & D \\
\hline & Capital cost & $\mathrm{F}$ & $E$ & B & $E$ & C & $\mathrm{D}$ & $\mathrm{F}$ & D & C \\
\hline & O\&M cost & C & B & $E$ & D & C & $\mathrm{F}$ & $\mathrm{F}$ & E & $\mathrm{F}$ \\
\hline & Human risk & F & G & $E$ & $\mathrm{~F}$ & D & $\mathrm{E}$ & $\mathrm{D}$ & $E$ & $E$ \\
\hline & Ecological risk & D & $E$ & $F$ & D & $E$ & C & $\mathrm{D}$ & $\mathrm{F}$ & $\mathrm{D}$ \\
\hline & Waste production & B & D & D & A & D & B & $E$ & G & C \\
\hline
\end{tabular}

\section{Results and discussion}

The results and statistics were obtained by following the proposed FSAHP approach. Figure 3, for example, depicts the probability density of the scores of each alternative with respect to the criterion of human health risk after 1,000 iterations. The histogram bar plot clearly demonstrates that heat treatment $(0.26-0.33)$ appeared to be the most attractive solution in terms of the lowest health risk, followed by ozone $(0.16-0.25)$ without any overlap. Ultrasound, biocide, and UV were seen as the least preferable option with considerable overlaps between each other, implying that experts were not confident about ranking one over the others. The correlation coefficients between the scores of ultrasound and biocide, biocide and UV, and ultrasound and UV were $-0.201,-0.476$, and 0.308 , respectively. A negative correlation coefficient between two variables usually implies that the increase of one variable is associated with the decrease of the other. One the other hand, a positive correlation coefficient means that two variables increase (or decrease) simultaneously in the same

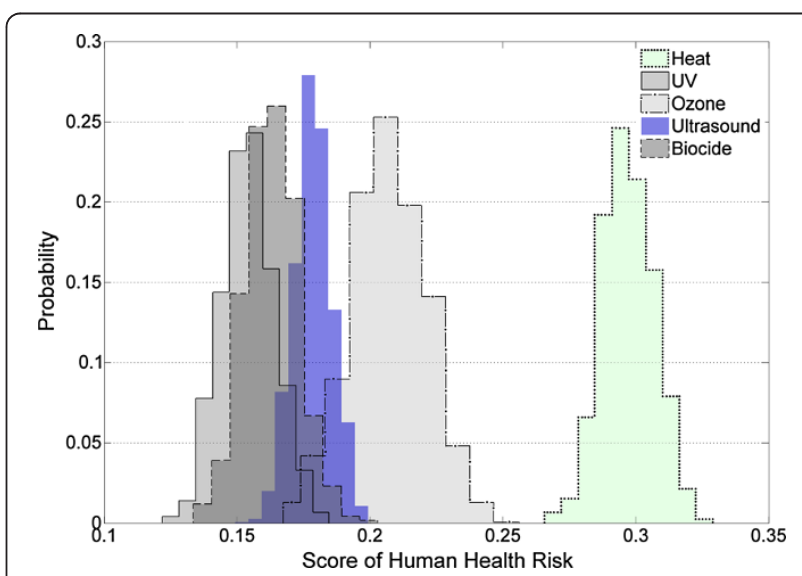

Figure 3 Probability distributions of alternative scores with regard to human risk. 
direction. These principles become more prominent as the absolute value of a correlation coefficient close to 1 . In this case study, negative correlation coefficients can be interpreted as larger overlaps as compared to positive correlation coefficients based on the fact that the scores were closely distributed (Figure 3). Tables 3 and 4 further validate these conclusions by showing the ranking of alternative priorities based on the COG and Chen's defuzzification methods, respectively. A statistical test of the null hypothesis that heat treatment was not the probabilistic optimal alternative (versus the alternate assumption that it was) was conducted to examine if the difference between it and the second best option (i.e., ozone) was statistically significant. Heat treatment was ranked first by both methods with the confidence level exceeding 95\%, indicating the null assumption that it is not probabilistic optimal (versus the alternate assumption that it is) is rejected. Ultrasound took the third place in more than $75 \%$ of the iterations while UV had the least preference in over $70 \%$ of the cases. From the technical perspective, the results were expected because heat sources such as waste heat from the engine jacket coolers and additional auxiliary boiler are usually not accessible by most crew members. On the other hand, short-term exposure to high level ozone can temporarily influence lung function and respiratory tract; meanwhile, some by-products (e.g., bromate) produced from ozonation may also pose risks to human health. UV was ranked as the least preferable alternative because excessive human exposure to UV is positively associated with severe health problems including photoaged skin, ocular diseases, and skin cancers.

The probability density distributions of criteria weights using the kernel-smoothing method are plotted in Figure 4. It reveals that efficacy on microorganisms, adaptability to harsh environments, O\&M cost, and human health risk were the most influential criteria that need to be prioritized in the decision making process. The overall scores of each alternative towards the goal are shown in Figure 5 as histograms. Another statistical test of the null hypothesis that UV was not the probabilistic optimal alternative (versus the alternate assumption that it

Table 3 Ranking with regard to human risk based on the COG method

\begin{tabular}{llllll}
\hline $\begin{array}{l}\text { Treatment } \\
\text { technology }\end{array}$ & $\mathbf{1}$ & $\mathbf{2}$ & $\mathbf{3}$ & $\mathbf{4}$ & $\mathbf{5}$ \\
\cline { 2 - 6 } & 1000 & 0 & 0 & 0 & 0 \\
Heat & 0 & 3 & 6 & 260 & 731 \\
UV & 0 & 943 & 51 & 6 & 0 \\
Ozone & 0 & 50 & 798 & 150 & 2 \\
Ultrasound & 0 & 4 & 145 & 584 & 267 \\
Biocide & 1000 & 1000 & 1000 & 1000 & 1000 \\
Total & & & & & \\
\hline
\end{tabular}

Table 4 Ranking with regard to human risk based on Chen's method

\begin{tabular}{llllll}
\hline $\begin{array}{l}\text { Treatment } \\
\text { technology }\end{array}$ & $\mathbf{1}$ & $\mathbf{2}$ & $\mathbf{3}$ & $\mathbf{4}$ & $\mathbf{5}$ \\
\cline { 2 - 6 } Heat & 1000 & 0 & 0 & 0 & 0 \\
UV & 0 & 2 & 20 & 277 & 701 \\
Ozone & 0 & 929 & 57 & 11 & 3 \\
Ultrasound & 0 & 64 & 752 & 180 & 4 \\
Biocide & 0 & 5 & 171 & 532 & 292 \\
Total & 1000 & 1000 & 1000 & 1000 & 1000 \\
\hline
\end{tabular}

was) was conducted. Tables 5 and 6 reveal that UV was ranked with the highest overall score at $100 \%$ confidence level, indicating that the null assumption that it was not probabilistic optimal (versus the alternate assumption that it is) was rejected. Ozone, heat treatment, and ultrasound had the second, third, and fourth places at the confidence levels of $61.0-71.4 \%, 56.0-68.4 \%$, and $78.4-$ $84.6 \%$, respectively. Figure 6 further supports this ranking scheme by using box plot to graphically illustrate the minimum, lower quartiles, medians, upper quartiles, and maximum of the overall scores. It indicates that the score distribution of ozone has a remarkable overlap with that of ultrasound as their medians, lower percentiles, and upper percentiles are close to each other. Nonetheless, ozone has a wider spread of scores as compared to ultrasound, suggesting that the experts were more unanimous on the performance of ultrasound during their assessment. Another interesting point to note is that both COG and Chen's methods produced similar defuzzification results, which demonstrated their applicability in the proposed FSAHP approach. In addition, the results also depicted that the proposal approach can well address linguistic inputs in group decision making

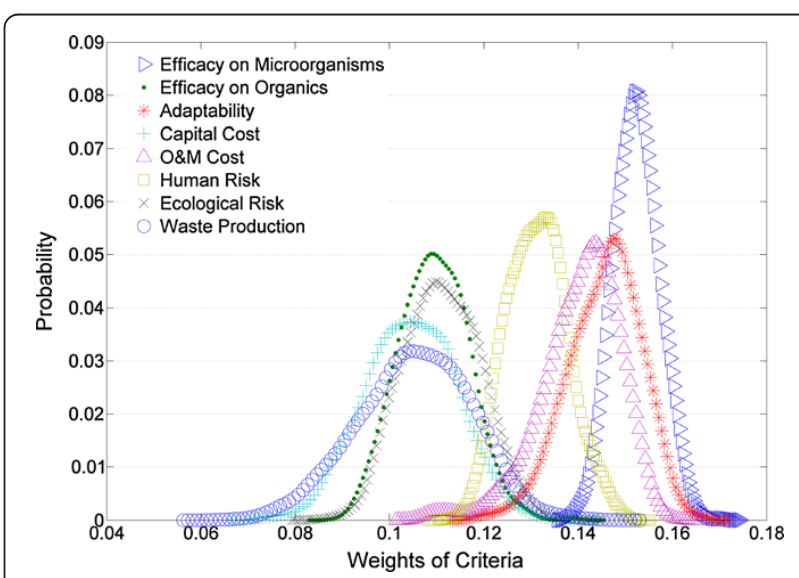

Figure 4 Probability density estimates of decision criteria weights. 


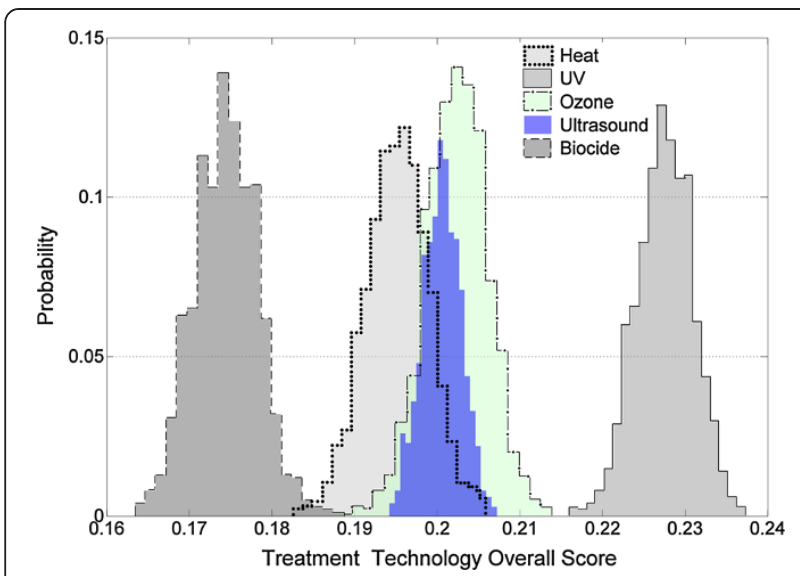

Figure 5 Probability distributions of alternative overall scores.

processes. The decision makers would be more comfortable and confident to give vague judgments rather than evaluating pairwise comparisons using single numeric values. Verbal assessments were collected and compared against with each other wherein the priorities of each alternative were determined. The use of the beta-PERT distribution was also able to lessen the uncertainty caused by insufficient information or biased opinions.

\section{Conclusions}

As one of the most widely exploited multi-criteria decision making (MCDM) approaches, the analytic hierarchy process (AHP) has been well documented in the literature. However, it has been criticized for its inability to quantify the uncertainty associated with decision making. In this paper, a hybrid fuzzy stochastic analytical hierarchy process (FSAHP) approach was developed in order to assist decision making with more confidence by integrating fuzzy set theory, probabilistic distribution, pairwise comparison and Monte Carlo simulation. A case study related to ballast water management was carried out to verify the feasibility and efficiency of the proposed approach. Five treatment technologies were evaluated against a number of environmental, economic,

Table 5 Summary of the simulation results for the final ranking based on the COG method

\begin{tabular}{llllll}
\hline $\begin{array}{l}\text { Treatment } \\
\text { technology }\end{array}$ & $\mathbf{1}$ & $\mathbf{2}$ & $\mathbf{3}$ & $\mathbf{4}$ & $\mathbf{5}$ \\
\cline { 2 - 6 } Heat & 0 & 71 & 144 & 784 & 1 \\
UV & 1000 & 0 & 0 & 0 & 0 \\
Ozone & 0 & 610 & 296 & 94 & 0 \\
Ultrasound & 0 & 319 & 560 & 121 & 0 \\
Biocide & 0 & 0 & 0 & 1 & 999 \\
Total & 1000 & 1000 & 1000 & 1000 & 1000 \\
\hline
\end{tabular}

Table 6 Summary of the simulation results for the final ranking based on Chen's method

\begin{tabular}{llllll}
\hline $\begin{array}{l}\text { Treatment } \\
\text { technology }\end{array}$ & $\mathbf{1}$ & $\mathbf{2}$ & $\mathbf{3}$ & $\mathbf{4}$ & $\mathbf{5}$ \\
\cline { 2 - 6 } Heat & 0 & 25 & 98 & 876 & 1 \\
UV & 1000 & 0 & 0 & 0 & 0 \\
Ozone & 0 & 746 & 218 & 36 & 0 \\
Ultrasound & 0 & 229 & 684 & 87 & 0 \\
Biocide & 0 & 0 & 0 & 1 & 999 \\
Total & 1000 & 1000 & 1000 & 1000 & 1000 \\
\hline
\end{tabular}

and technical criteria by nine experts. The results revealed that UV was ranked with the highest overall score at $100 \%$ confidence level, indicating that the null assumption that it was not probabilistic optimal (versus the alternate assumption that it is) was rejected. Ozone, heat treatment, and ultrasound had the second, third, and fourth places at the confidence levels of $61.0-71.4 \%$, 56.0-68.4\%, and 78.4-84.6\%, respectively. Considerable overlaps existed among these three alternatives which may be attributed to the irreducible uncertainty caused by subjective judgments or lack of knowledge. The results also revealed that both COG and Chen's defuzzification methods were able to provide the decision makers with reliable decision references. The proposed FSAHP approach can offer a number of benefits such as the capability of capturing human's appraisal of ambiguity and addressing the effects of uncertain judgment when dealing with insufficient information or biased opinions. However, this approach is highly sensitive to expert dependence whereby any misjudgment may affect its reliability and efficiency. As a complex methodology, it requires more computational efforts in assessing composite priorities than the traditional AHP.

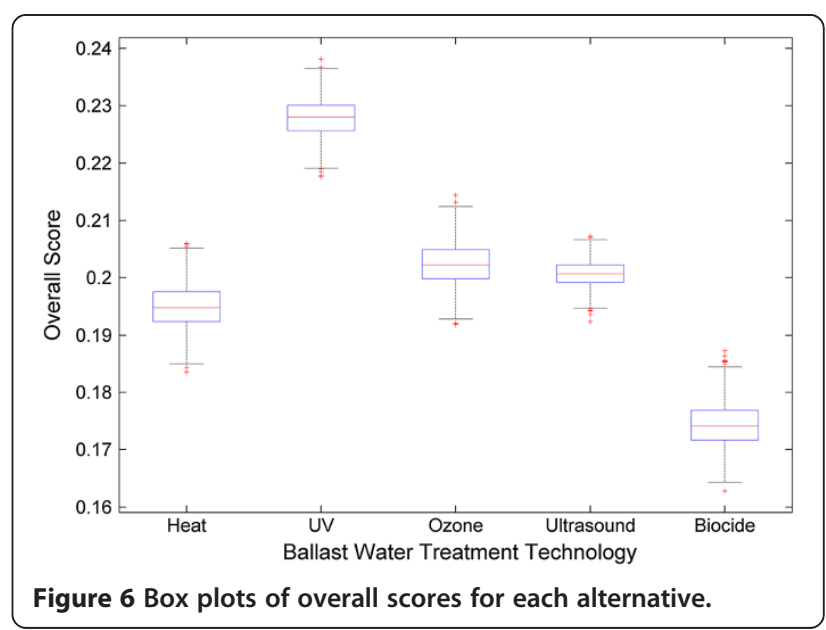




\section{Competing interests}

The authors declared that they have no competing interest.

\section{Authors' contributions}

$L$ and BC co-developed the FSAHP method for group decision-making and conducted the design of the study. BZ and HP participated in the design of questionnaire, acquisition of data and data analysis. $L J$ performed data analysis and drafted the manuscript, which BC, BZ and HP helped edit and polish. All authors have read and approved the final manuscript.

\section{Acknowledgements}

Special thanks go to American Bureau of Shipping Harsh Environment Technology Centre (ABS-HETC), Research \& Development Corporation Newfoundland and Labrador (RDC NL), Natural Sciences and Engineering Research Council of Canada (NSERC), and Memorial University of Newfoundland for funding this work.

Received: 27 August 2013 Accepted: 4 November 2013 Published: 9 November 2013

\section{References}

1. Kiker GA, Bridges TS, Varghese A, Seager TP, Linkov I: Application of multicriteria decision analysis in environmental decision making. Integr Environ Assess Manage 2005, 1(2):95-108.

2. Matott LS, Babendreier JE, Purucker ST: Evaluating uncertainty in integrated environmental models: a review of concepts and tools. Water Resour Res 2009, 45. doi:10.1029/2008WR007301.

3. Steele K, Carmel Y, Cross J, Wilcox C: Uses and misuses of multicriteria decision analysis (MCDA) in environmental decision making. Risk Anal 2008, 29(1):26-33.

4. Yeh $\mathrm{CH}$, Chang $\mathrm{YH}$ : Modeling subjective evaluation for fuzzy group multicriteria decision making. Eur J Oper Res 2009, 194(2):464-473.

5. Yu L, Wang S, Lai KK: An intelligent-agent-based fuzzy group decision making model for financial multicriteria decision support: the case of credit scoring. Eur J Oper Res 2009, 195(3):942-959.

6. Kornyshova E, Salinesi C: MCDM techniques selection approaches: state of the art. In Proceedings of the 2007 IEEE Symposium on Computational Intelligence in Multi-Criteria Decision-Making (MCDM), Honolulu. 2007.

7. Saaty TL: The Analytic Hierarchy Process: Planning, Priority Setting and Resource Allocation. New York, NY, USA: McGraw-Hill; 1980.

8. Chowdhury $S$, Husain T: Evaluation of drinking water treatment technology: an entropy-based fuzzy application. J Environ Eng-ASCE 2006, 132(10):1264-1271.

9. Jablonsky J: Measuring the efficiency of production units by AHP models. Math Comput Modell 2007, 46:1091-1098.

10. Kaya T, Kahraman C: An integrated fuzzy AHP-ELECTRE methodology for environmental impact assessment. Expert Syst App/ 2011, 38:8553-8562.

11. Sadiq R, Tesfamariam S: Environmental decision-making under uncertainty using intuitionistic fuzzy analytic hierarchy process (IF-AHP). Stoch Env Res Risk A 2009, 23(1):75-91.

12. Tiryaki F, Ahlatcioglu B: Fuzzy portfolio selection using fuzzy analytic hierarchy process. Inform Sci 2009, 179:53-69.

13. Tolga E, Demircan ML, Kahraman C: Operating system selection using fuzzy replacement analysis and analytic hierarchy process. Int J Prod Econ 2005, 97:89-117.

14. Deng $\mathrm{H}$ : Multicriteria analysis with fuzzy pair-wise comparison. Int J Approximate Reasoning 1999, 21:215-231.

15. Banuelas R, Antony J: Modified analytic hierarchy process to incorporate uncertainty and managerial aspects. Int J Prod Res 2004, 42(18):3851-3872.

16. Rosenbloom ES: A probabilistic interpretation of the final rankings in AHP. Eur J Oper Res 1996, 96:371-378.

17. Carlucci D, Schiuma G: Applying the analytic network process to disclose knowledge assets value creation dynamics. Expert Syst App/ 2009, 36(4):7687-7694

18. Yu CS: A GP-AHP method for solving group decision-making fuzzy AHP problems. Comput Oper Res 2002, 29:1969-2001.

19. Tesfamariam S, Sadiq R: Risk-based environmental decision-making using fuzzy analytic hierarchy process (F-AHP). Stoch Env Res Risk A 2006, 21:35-50.

20. Eskandari $H$, Rabelo L: Handling uncertainty in the analytic hierarchy process: a stochastic approach. Int J Inf Tech Decis 2007, 6(1):177-189.
21. Jing $L$, Chen B, Zhang BY, Li P: A hybrid stochastic-interval analytic hierarchy process (SIAHP) approach for prioritizing the strategies of reusing treated wastewater. Math Probl Eng 2013. doi:10.1155/2013/874805

22. Hsu T, Pan FFC: Application of Monte Carlo AHP in ranking dental quality attributes. Expert Syst App/ 2009, 36:2310-2316.

23. Phanikumar CV, Maitra B: Valuing urban bus attributes: an experience in Kolkata. J Publ Transport 2006, 9(2):69-87.

24. Coates G, Rahimifard S: Modelling of post-fragmentation waste stream processing within UK shredder facilities. Waste Manage 2009, 29(1):44-53.

25. Jing L, Chen B, Zhang BY, Li P, Zheng JS: A Monte Carlo simulation aided analytic hierarchy process (MC-AHP) approach for best management practices assessment in nonpoint source pollution control. J Environ Eng-ASCE 2012, 139(5):618-626.

26. Endresen $\varnothing$, Behrens $H L$, Brynestad $S$, Andersen AB, Skjong R: Challenges in global ballast water management. Mar Pollut Bull 2004, 48:615-623.

27. Cangelosi AA, Mays NL, Balcer MD, Reavie ED, Reid DM, Sturtevant R, Gao X: The response of zooplankton and phytoplankton from the North American Great Lakes to filtration. Harmful Algae 2007, 6:547-566.

28. Galil BS, Nehring S, Panov V: Waterways as invasion highways - impact of climate change and globalization. Ecol Stud 2007, 193(2):59-74.

29. Jing $L$, Chen $B$, Zhang $B Y$, Peng $H X$ : A review of ballast water management practices and challenges in harsh and arctic environments. Environ Rev 2012, 20:83-108.

30. Parmesan C: Ecological and evolutionary responses to recent climate change. Annu Rev Ecol Evol Syst 2006, 37:637-669.

31. Gollasch S, David M, Voigt M, Dragsund E, Hewitt C, Fukuyo Y: Critical review of the IMO international convention on the management of ships' ballast water and sediments. Harmful Algae 2007, 6:585-600.

32. Gregg MD, Hallegraeff GM: Efficacy of three commercially available ballast water biocides against vegetative microalgae, dinoflagellate cysts and bacteria. Harmful Algae 2007, 6:567-584.

33. Zadeh LA: Fuzzy Sets. Inform Contr 1965, 8:338-353.

34. Kaufmann A, Gupta MM, Kaufmann A: Introduction to fuzzy arithmetic: theory and applications. New York: Van Nostrand Reinhold Company; 1985.

35. Li P, Chen B: FSILP: Fuzzy-stochastic-interval linear programming for supporting municipal solid waste management. J Environ Manage 2011, 92:1198-1209.

36. Dawes J: Do data characteristics change according to the number of scale point used? Int J Market Res 2007, 50(1):61-77.

37. Ramík J, Korviny P: Inconsistency of pair-wise comparison matrix with fuzzy elements based on geometric mean. Fuzzy Sets Syst 2010, 161:1604-1613.

38. Chen SJ, Hwang CL: Fuzzy multiple attribute decision making. Heidelberg Springer; 1992.

39. Herwig RP, Cordell JR, Perrins JC, Dinnel PA, Gensemer RW, Stubblefield WA, Ruiz GM, Kopp JA, House ML, Cooper WJ: Ozone treatment of ballast water on the oil tanker S/T Tonsina: chemistry, biology and toxicity. Mar Ecol Prog Ser 2006, 324:37-55.

40. Holm ER, Stamper DM, Brizzolara RA, Barnes L, Deamer N, Burkholder JM: Sonication of bacteria, phytoplankton and zooplankton: Application to treatment of ballast water. Mar Pollut Bull 2008, 56:1201-1208.

41. de Lafontaine Y, Despatie SP, Veilleux É, Wiley C: Onboard ship evaluation of the effectiveness and the potential environmental effects of PERACLEAN ${ }^{\circledR}$ Ocean for ballast water treatment in very cold conditions. Environ Toxicol 2009, 24(1):49-65.

42. Tsolaki E, Diamadopoulos E: Technologies for ballast water treatment: a review. J Chem Technol Biotechnol 2010, 85:19-32.

doi:10.1186/2193-2697-2-10

Cite this article as: Jing et al:: A hybrid fuzzy stochastic analytical hierarchy process (FSAHP) approach for evaluating ballast water treatment technologies. Environmental Systems Research 2013 2:10. 